ISSN: 0212-0267

DOI: https://doi.org/IO.I42OI/hedu2O2I40323345

\title{
LA EDUCACIÓN COMO ACTO DE SEDUCCIÓN
}

\section{Education as an act of seduction}

\author{
Natalia PAIs Álvarez \\ Universidad de La Laguna \\ Correo-e: natalyapais@gmail.com \\ M. ${ }^{a}$ Lourdes GonZÁLEZ-LuIS \\ Universidad de La Laguna \\ Correo-e: mlgonzal@ull.edu.es
}

Recibido: 30 de junio de 2020. Envío a informantes: 9 de julio de 2020.

Aceptación definitiva: 13 de noviembre de 2020

RESUMEN: El propósito de este trabajo es ofrecer un retrato discursivo acerca de la realidad educativa en nuestro momento histórico, cada vez más amenazada por la posverdad. La verdad se ha convertido en algo aburrido que no despierta interés educativo alguno. Consecuentemente, es necesario un compromiso pedagógico que contribuya a desenmascarar la manipulación y las mentiras informativas.

Desde un enfoque hermenéutico, se analiza en qué medida es necesario un proyecto educativo ético-estético, anclado en la realidad múltiple, crítico, transformador y facilitador de estrategias que permitan alcanzar una vida digna para todos y todas y entre todas y todos.

Tras el gran aparataje mediático que muestra una sociedad conectada, se esconden también historias silenciadas de sujetos ensimismados, manipulados, urgidos de formar parte de las cibercosmópolis para dar salida a su necesidad comunitaria de integración, como única tabla de salvación para la no exclusión. Solo desde una educación seductora puede contrarrestarse esta realidad.

PalabRas Clave: posverdad; desvelamiento; hermenéutica pedagógica; proyecto ético-estético; educación y seducción.

AвSTRACT: The purpose of this work is to offer a speech about the educational reality in our historical moment, more and more threatened by the post-truth. The truth has become something boring to be avoided and whose search does not 
arouse any educational interest. Consequently, it is necessary a pedagogical commitment that contributes to unmask the manipulation and the fake news.

Using a hermeneutic approach, we will analyze why we need an ethical-aesthetic educational project, anchored in multiple reality, critical, transformative and capable of facilitating strategies to achieve a dignified life for all of us.

Behind a mass-mediated society that apparently serves to connect people, there are also silenced stories of self-absorbed and manipulated subjects, urged to be part of the cybercosmopolis. Only a seductive education could counteract social exclusion and serve a project of community integration.

KEY WORDS: post-truth; revelation; pedagogical hermeneutics; ethical-aesthetic project; education and seduction.

\section{Elogio del afuera}

El aburrimiento es el deseo de felicidad dejado en estado puro. Giacomo Leopardi

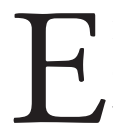
L ARTE DE ENSEÑAR ofrece una partitura infinita que multiplica las posibilidades ético-estéticas. Es un arte que busca el afuera, hacer salir, como mayéutica guiada, desde dentro hacia un afuera común, hacia el espacio que se comparte en el momento del acto educativo. Si se extrae la potencia, lo mejor, lo que construye comunidad, el acto de retractarse o de atreverse, etc., ahí se está martillando y enseñándose a martillar. La seducción es siempre fugaz, pero puede dejar una estela en el tiempo. Es ese momento de suspensión en el afuera del ser, cuando el entusiasmo por el conocimiento rompe la barrera del tedio y alcanza la altura de algo atractivo, que comunica, que dice, que es palabra con sabor, con olor, con tacto, con sentido y sentida en comunidad. Es decir, mueve puntualmente numerosas realidades interiores hacia un afuera compartido para construir otra realidad común y pretendidamente mejor.

Si nos preguntáramos cuál es el reto educativo de nuestro tiempo, responderíamos que una educación ético-estética, anclada en la realidad múltiple, crítica, transformadora y facilitadora de estrategias que permitan alcanzar una vida digna para todos y todas y entre todas y todos. Este proyecto se plantea en una sociedad cada vez más compleja en la que el acceso a la información es más fácil y democrático que nunca, pero también más encriptado. Se acentúa el dato trivial, espectacular y muchas veces falso. La búsqueda de protagonismo y de espacios de captación se pretende más importante que la sustancia que da cuerpo al foco de atención.

El momento de ars erotica es, por otra parte, tan fugaz como peligroso. El o la docente se abandona a sí mismo. Unas veces ofrece una chispa para la acción,

Cfr. Agamben, G.: Lo abierto. El hombre y el animal, Valencia, Pre-textos, 2005, p. 83. 
otras, deviene en propio sujeto de fascinación. Hace e invita a hacer, agente y cómplice simultáneamente, de la fascinación de un encuentro irrepetible.

La sociedad del XXI es una suerte de laberinto de espejos multiformes donde ofrecerse y desde donde mirar el reflejo de los demás. Espectáculo y verdad son puestos a competir. La verdad se ha convertido en algo aburrido que hay que sortear y su búsqueda no despierta interés alguno. No hay límites entre la verdad y la mentira, la virtud y el dolo. El tiempo tiene una medida vertiginosa dada por la urgencia, por la necesidad de conferir un sentido utilitario e inmediato a toda acción (cultura urgida de satisfacción instantánea). No se interprete la Verdad como absoluto, sino con minúscula, como horizonte imposible pero necesario para renegar conscientemente de la mentira teledirigida. Difícil reto, pues, como plantea Ordine, «mientras que todo sea objeto de crítica y condena "salvo el dinero", cualquier cosa que "se asemeje a la virtud” será considerada "inmensamente ridícula”. Incluso la justicia prohibirá la existencia de aquellos ciudadanos incapaces de enriquecerse" ${ }^{2}$.

Estos imaginarios paradigmáticos de pensamiento único que se han impuesto son cantos de sirena que limitan el pensamiento crítico. Afrontar la ingente cantidad de espejismos de la travesía, esos que conducen a vidas paralelas donde las narrativas del mal continúan ofreciéndose como más seductoras, exige de quienes se dedican a educar clases de canto de sirena.

Tras el gran aparataje mediático que muestra una sociedad conectada, se esconden también las historias silenciadas de sujetos ensimismados, manipulados, urgidos de formar parte de las cibercosmópolis como necesidad comunitaria de integración, como tabla de salvación para la no exclusión. Podríamos, junto a McIntyre, decir que el mundo contemporáneo es un mundo posterior a toda virtud, o al menos posterior a las virtudes de la humildad, la generosidad, la compasión o la justicia, reemplazadas ahora por el individualismo, la soberbia, la libre competencia y la indiferencia.

¿Qué es lo que define las directrices de un sistema de educación? ¿Cuál es su futuro? ¿La pandemia lo ha reforzado o contribuye a poner en evidencia sus miserias? ¿Cómo se «virtualiza» el arte de la seducción tras la pantalla de metacrilato o tela que opacan nuestras voces? El propósito es, como mínimo, que no las silencie. En las últimas décadas ha proliferado una abundante literatura en torno a la necesidad de rescatar y devolver las emociones al terreno de la educación. Vale

Ordine, N.: La utilidad de lo inútil, Barcelona, Acantilado, 20I7, p. 63. Más adelante dice sobre el objeto de la verdad: «La persecución y la caza corren propiamente de nuestra cuenta; no tenemos excusa si las efectuamos mal y fuera de propósito. Fallar en la captura es otra cosa. Porque hemos nacido para buscar la verdad; poseerla corresponde a una potencia mayor [...] El mundo es solo una escuela de indagación. Lo importante no es quién llegará a la meta, sino quién efectuará las más bellas carreras» (p. I27).

La BBC ha comentado recientemente un documental (El dilema de las redes sociales, estrenado en la plataforma Netflix) en el que se expone cómo funcionan las redes sociales y qué estrategias para captar usuarios y generar adicción a la conexión emplean quienes las dirigen. En https://www. bbc.com/mundo/noticias-54385775, consultado el o6 de octubre de 2020. 
la pena recordar que la exaltación de las libertades individuales, de los ideales de vida buena realizables en la esfera de la vida privada, es una herencia de la Modernidad. Aquí no podíamos detenernos en una historia de las ideas que mostrara las continuidades y las diferencias entre el pensamiento aristotélico y el pensamiento moderno en torno al primado de lo comunitario sobre lo individual o viceversa, historia que, por otra parte, ha sido la piedra de toque de esquematismos conceptuales mediante los cuales se analizan las corrientes políticas contemporáneas (liberalismo, comunitarismo, republicanismo).

Pero, junto a esas libertades, educar exige domeñar la balanza entre el equilibrio y la emoción, entre lo justo y lo legal. La seducción ha de atravesar la apariencia y alcanzar una discursiva social y política, especialmente ahora, que las incertidumbres y el confinamiento que ha modificado el espacio, el tiempo y las metodologías en las aulas exigen un trabajo en paralelo que atienda a la ética y la estética, a la razón y a la emoción, que den sentido a un proyecto que, aun pautado, precisa y precisará la tecné de la improvisación.

Los efectos económicos de la pandemia pondrán en evidencia las costuras del tejido social y sus recortes. Transitar la injusticia reclama una reflexión sobre la justicia. «Lo justo», como señala Ricoeur ${ }^{4}$, emana de un sentimiento que proviene de lo que se considera «injusto», de la percepción de que se ha franqueado el espacio de la dignidad, de la indignación ante acciones que nos colocan en una situación de indefensión. Lo justo es, desde una perspectiva estrictamente individual, la reparación del daño recibido.

Toda crisis inaugura el riesgo de estallidos y regresiones a morales rígidas asociadas a un éxito ético pretérito que tiene más de nostalgia que de autenticidad. Del talión al pacto social, se ha venido conformando una racionalidad legalista, ampliamente difundida en nuestras sociedades occidentales, $y$ ha propiciado una conciencia común acerca del carácter reprobatorio que tiene el hecho de tomarse la justicia, como se dice comúnmente, por cuenta propia. Y este es sin duda un avance civilizatorio en la medida en la que ha posibilitado cierto orden social, puesto que ha permitido la contención de respuestas o de impulsos violentos y la deconstrucción simbólica de la relación sinonímica entre venganza y justicia. De este modo, el avance del Estado de Derecho y el desarrollo cada vez más enmarañado de normas jurídicas han contribuido a la conformación de subjetividades del bien: del bien común, de la empatía, del perdón, de la serenidad, de la compasión, de la clemencia, etc. Incluso del concepto de amnistía, que, si bien tiene numerosos detractores que cuestionan su capacidad reparadora ya que solo favorece a quien infringe un daño, no a su víctima (lo cual puede entenderse como una forma de violencia simbólica que podría ser contraproducente si la víctima no muestra su acuerdo con la institución que la proclama), se situaría dentro de la línea de conceptos jurídicos del derecho positivo.

Vemos pues que, en su propia esencia, incluso el paradigma racionalista contiene emociones. Y esto demuestra el indisoluble vínculo entre justicia y

4 Ricoevr, P.: Lo justo, Madrid, Caparrós editores, 1999, p. 23. 
emoción. La relación entre Derecho y emociones se da tanto desde una perspectiva según la cual el Derecho coadyuva a la contención legal de emociones llamémoslas negativas como la ira, los celos, la enemistad, la humillación, el asco, la indignación, pero también a favorecer sentimientos positivos como la conmoción, la reparación de la dignidad, el perdón, etc.

En este punto es preciso matizar que, como pertinentemente expone Martha Nussbaum', en realidad las emociones no son ni negativas ni positivas, sino que dependen de las situaciones o contextos en los que emergen y que unas y otras pueden ser tan necesarias como deleznables.

Ahora bien, cabe distinguir, como plantea Erica Baum, dos tipos de emociones: las básicas y las morales. Las primeras son instintivas y compartidas con los animales. Las segundas, en cambio, son específicamente humanas e «interactúan con la razón revelando la vulnerabilidad inherente a los seres humanos»; esto es, no son sensaciones meramente biológicas, sino que «dan cuenta de un punto de vista moral» ${ }^{6}$.

Por lo tanto, son emociones políticas que están presentes, implícita o explícitamente, en el pacto social, y forman parte esencial en el ejercicio de deliberación colectiva de las normas, entre ellas, las educativas.

Las emociones entroncan con la vida social e individual y atraviesan a las propias instituciones. Afectan, pues, a la vida pública y a la propia decisión de los individuos de lo que se considera bueno y justo, si bien esto es algo que las teorías morales utilitaristas no han contemplado. Estas han adolecido, como indica Amartya Sen, de tender a caracterizar sociedades perfectamente justas y a no valorar cómo se avanza hacia la justicia o cómo reducir la injusticia. Del mismo modo que la noción de lo justo proviene de la percepción de lo injusto, al derecho le es fundamental tener en cuenta la vulnerabilidad en la medida en que uno de sus objetivos fundamentales es la protección de sus ciudadanos. Las emociones, en este sentido, devuelven al derecho un vínculo con la ciudadanía, con sus sentimientos, con sus necesidades y, en última instancia, con la ética.

Amartya Sen cuenta que en la antigua filosofía jurídica india se tenían dos conceptos diferentes de justicia: niti y nyasa. La primera idea, «niti, se refiere a la idoneidad de las instituciones, así como a la corrección del comportamiento, mientras que la segunda, nyasa, alude a lo que surge y a cómo surge, y en especial a las vidas que las personas son realmente capaces de vivir» ${ }^{7}$.

Si se asume que contenemos o que somos capaces de sentir tanto las emociones básicas como las morales, y de que somos potencialmente susceptibles de unas y otras, podríamos abocar en una lectura positiva que nos haga conscientes de una más compleja percepción de nosotros mismos, pero ello no significa que

Nussbaum, M.: Emociones politicas. ¿Por qué el amor es importante para la justicia?, Barcelona, Espasa, 20I4, p. 39.

6 BAum, E.: "El rol de las emociones en la esfera pública", Revista Latinoamericana de Derechos Humanos Volumen, Universidad Nacional Costa Rica, 23, I semestre (2012), p. 48.

SEN, A.: La idea de la justicia, Madrid, Santillana, 20I0, p. I9. 
determinadas emociones, aun cuando sean «naturales», sean legítimas o deban tener cabida en el Derecho.

La inclusión de la emoción en el marco jurídico no se traduce en una naturalización de emociones como la exaltación, el insulto o el asco, sino en cómo reaccionamos ante estas. Niti y nyasa en este sentido no son dos conceptos ajenos. La ciudadanía y sus instituciones deben intentar dar respuesta a eso que surge. Así pues, quizá podamos de nuevo convenir con Martha Nussbaum en que ninguna teoría del derecho puede tener en cuenta emociones de ese lado.

La emoción del «poder» se ha relevado como eje que está en el centro de todo análisis social, político, económico y, por ende, jurídico. Se analiza comúnmente como relación, como deseo, y su envés es la corrupción. Existe incluso una «Declaración sobre los principios fundamentales para las víctimas de delitos y abusos de poder ${ }^{8}$, pero el poder entendido como emoción, el poder como tal, está legitimado y es legal.

Aquí, la vieja e infrautilizada cultura del ocio, de corte evasivo, se trastoca en la nueva herramienta de control -la nueva versión del viejo Pan y circo-con la inundación de un ocio invasivo. En cualquier caso, las artes se reutilizan, se mediatizan y mass-mediatizan mezquinamente, pero asumen el rol mercantil que corresponde a los tiempos, en detrimento de su auténtica misión creadora y transformadora.

En estos tiempos utilitarios, un saber refundador de la ética vendría a ser un saber que incorporara la asunción inexorable de la necesidad del ser, del ser consciente de sí mismo y del otro y de todos en el espacio común. Enseñar la refundación y hacerla atractiva es más complicado que proyectar la idea, pero sin esta no cabría posibilidad de praxis. Y lo que la hace precisamente complicada es la búsqueda inexorable del placer. Es posible sostener el discurso ético y político sobre la base de la búsqueda de la felicidad singular y plural, personal y colectiva, esta última en un doble sentido: con los otros próximos y en instituciones justas. En el soporte de esta tesis aquella afirmación de Ricoeur, según la cual la intencionalidad ética es «la intencionalidad de la «vida buena» con y para otro en instituciones justas»?.Y es en esa intencionalidad, en ese tender a la vida buena, donde lo pedagógico entra en escena. La educación se convierte en la mediación deliberativa, en el puente ético entre deseo y acto, entre el «ser» y el «ser en el mundo».

El primer eje de la intencionalidad ética es el deseo. Este deseo parte de la capacidad de hacerse responsable de las propias acciones; el reto deliberativo aquí girará en torno a los fines y los medios para alcanzar esa vida buena. Los ideales de vida buena pueden comprenderse en una 'unidad narrativa de la vida', donde el vínculo entre ética y narrativa es relevante, evidenciando que la tendencia hacia la vida buena, como deseo y deliberación, como vaivén entre ideales y prácticas,

8 Dictada por la Asamblea General de las Naciones Unidas (AG 40/34), el 29 de noviembre de I985, en su $96^{\circ}$ aniversario.

9 Ricoeur, P.: Sí mismo como otro, México, Siglo XXI, i996, p. 176. 
muestra la fragilidad humana y la imposibilidad de otorgar absolutos tanto a la voluntad como a la razón; asimismo asoma la in-completud del uno y la imbricación de las otras historias sin las cuales la propia carecería de sentido. Aparece el carácter reflexivo de la intencionalidad ética que consiste en la posibilidad siempre abierta de llevar a cabo un ejercicio hermenéutico de la vida misma. Es a este primer eje de la intencionalidad ética al que vinculamos una Pedagogía del deseo. Es confiar en la posibilidad de hacer coincidir el 'obrar bien' con el 'vivir bien'.

El segundo eje sobre el que gira esta propuesta ética es la solicitud. Es la apuesta que contrapone cualquier atisbo de interpretación individualista del «buen vivir». Se abre aquí la puerta del carácter dialógico inherente al acto ético-pedagógico. Se reclama la necesaria mediación del otro en el trayecto. El otro que irrumpe e interrumpe. El otro imprescindible en la auténtica bondad de la vida. La alteridad del 'otro sí', el prójimo, donde se modela y ejercita el sentimiento de amistad, de hospedaje en doble vía, la de acoger y ser acogido. El desprendimiento del yo como condición de la plenitud del sí.

Es así pues que la auténtica solicitud es la que compensa la desigualdad de poder en la reciprocidad del intercambio, poniendo a prueba el sí mismo al enfrentarlo a su propia vulnerabilidad y finitud. Una Pedagogía de la solicitud es pues, la que corresponde a este segundo eje de intencionalidad ética. La Educación como acto de hospitalidad, tiempo y espacio de acogida, darle el lugar al que llega. Acontecimiento de radical novedad: el hospedaje. De no existir el magisterio, se reinventaría para dar paso a la política como acto posibilitador de amor. Pero para que toda esta propuesta ética no se funde exclusivamente en las relaciones de cercanía o vecindad, en el cara a cara (eso dejaría en suspenso la sociedad, la cultura, la historia, en tanto en ellas no siempre prevalece la proximidad), insistiremos en que el hombre «capaz» sólo es 'esbozo de hombre' sin la mediación institucional, sin la pertenencia a un cuerpo político. «Es en el ser-entre donde el anbelo de vivir bien se realiza. Es como ciudadanos como llegamos a ser hombres. El anhelo de vivir en instituciones justas no significa otra cosa $»^{10}$. He aquí el fundamento del tercer eje de la intencionalidad ética, con un fuerte acento político en el asunto de la igualdad: «La institución como punto de aplicación de la justicia, y la igualdad como contenido ético de la justicia» ${ }^{\mathrm{II}}$.

La institución es la estructura del «vivir juntos» de una comunidad histórica, irreducible a las relaciones «interpersonales», pero consustancialmente unida a ellas; construida en el modelo de la distribución y desde la fórmula de «lo común» y no bajo reglas coercitivas. Cobran aquí relevancia la pluralidad y la concertación como instrumentos para la intencionalidad ética de una institución justa: «La pluralidad incluye terceros aunque no tengan rostro» ${ }^{12}$.

Ese «querer vivir juntos», que pudiera ser una decisión voluntaria entre amigos, se extiende, se amplía, se expande, convirtiéndose en meta de realización

- Ricoevr, P.: Lo justo, Madrid, Caparrós, p. 28.

Ibid., p. 202.

${ }^{12}$ Ibid., p. 204. 
histórica de proyectos comunes. Por otra parte, la idea de concertación tiene que ver con lo que Hanna Arendt llamó «espacio público de aparición»; es el seno de las prácticas, los planes de vida, la unidad narrativa de una vida, «el espacio de aparición cobra existencia siempre que los hombres se agrupan por el discurso y la acción, y por lo tanto precede a toda forma de constitución de la esfera pública $\mathrm{y}$ de las varias formas de gobierno $[\ldots]]^{13}$.

Ese espacio público que acoge y realiza el deseo de «vivir juntos» es una constante y frágil construcción; está en relación permanente con el «ejercicio del poder», encubierto e invisibilizado por las relaciones de dominación, y que suele emerger violentamente solo cuando está a punto de ser destruido.

Recordando nuevamente a Arendt:

El poder sólo es realidad donde palabra y acto no se han separado, donde las palabras no están vacías y los hechos no son brutales, donde las palabras no se emplean para velar intenciones sino para descubrir realidades, y los actos no se usan para violar y destruir sino para establecer relaciones y crear nuevas realidades ${ }^{14}$.

Sin embargo, la experiencia del poder ha estado ligada al ejercicio de la violencia y la negación del otro. Por ello, hemos insistido en la emergencia de la idea de justicia, en su formulación legal, confiriendo a la ley coherencia y derecho de restricción; y en su dimensión de lo bueno. El devenir de las prácticas judiciales de la justicia ha terminado distanciando una y otra dimensión. Y no es posible la aparición de la justicia sin el reconocimiento en igualdad de la diferencia. Un mundo gobernado por la razón del mercado, por leyes económicas que no están hechas para «quienes participan en la vida en común», hace parecer que la justicia, como virtud de las instituciones, está cediendo el paso ante un discurso según el cual cada quien tiene las mismas oportunidades de participar en los bienes públicos, pero en desigualdad de condiciones.

A este tercer y último eje de intencionalidad ética correspondería una Pedagogía del Reconocimiento. Una educación como acto de justicia, como lugar y tiempo de la reparación. La sanación de las heridas infligidas multisecularmente, la recuperación de la memoria olvidada, el rescate de las dignidades secuestradas. El fin del hecho alterativo no es solo el reconocimiento del otro, es promover que ocupe un espacio y un tiempo feliz en la historia que habita.

\section{Las ruinas del entusiasmo}

Vivimos de la seducción, pero morimos en la fascinación. Jean Baudrillard, De la seducción.

${ }^{13}$ Arendt, H.: La condición humana, Barcelona, Paidós, 1993, p. 222.

${ }^{14}$ Ibid., p. 223. 


\section{Decía Derrida:}

La ruina no sobreviene como un accidente a un monumento ayer intacto. Al comienzo, hay la ruina [...] ¿Cómo amar otra cosa distinta que la posibilidad de la ruina? ¿Otra cosa distinta que la totalidad imposible? El amor tiene la edad de esta ruina sin edad -a la vez originaria, incluso niña, y ya vieja- [...] La ruina no está ante nosotros, no es ni un espectáculo ni un objeto de amor. Es la experiencia misma: ni el fragmento abandonado pero todavía monumental de una totalidad, ni siquiera, como pensaba Benjamin, un tema de la cultura barroca. No es un tema, justamente, arruina el tema, la posición, la presentación o la representación de cualquier cosa ${ }^{15}$.

Porque no es un espectáculo, ni objetivable, en el acto educativo no tiene cabida la categoría de la excelencia ni la certeza de que al desarrollo de las «buenas prácticas» corresponderá el premio del logro o de la fascinación. Se pueden evaluar las estrategias metodológicas del diseño y la implementación, pero jamás el logro, que nunca está sujeto a la categoría de lo inmediato. En cualquier caso, enseñanza-aprendizaje y «resultado» están descompasados. Y aun cuando haya «logro» jamás se tendrá la certeza de a quién se debe. La calificación apenas ofrece una osada muestra de un proceso no solo inabarcable, sino incapaz de prever las contingencias futuras.

El acto educativo es un acto-ruina. Está abocado al fracaso, a la incertidumbre y a la suma de interpretaciones que andan muy lejos de asemejarse a intención de quien ofrece espacios de reflexión y acción. Y este no es el fracaso de quien enseña ni de quien aprende. Es un fracaso sin agente, como la ruina derridiana: no está ante nosotros, es la experiencia misma. No es el espectáculo del fracaso, sino el necesario fracaso que subyace a todo intento. La ruina no limita ni ha de impedir el acto de seducción, de la misma manera que vivir con la certeza de la muerte inminente no nos impide vivir, aun sabiéndonos muertos. De la misma manera que se evalúa. Como todo trayecto, está lleno de claroscuros e incertezas, como acaso en la vida no se atina tampoco a afinar en el diagnóstico del error y el acierto. También conviene plantearse que lo que se abona tiene efectos diversos, como bumeranes unas veces, como gratificación otras, como lección siempre.

$\mathrm{El}$ ars erotica es el pulso incierto entre el entusiasmo y el fracaso. La sensación fugaz de fascinación es lo que motiva a continuar en esta brega colectiva que es la enseñanza. Sin embargo, esta fascinación cumple una función mediadora, puntual, actoral. Parece claro que parte del rechazo a la escuela se atribuye a cuestiones metodológicas. Sin embargo, la cuestión es más compleja. Las tendencias desescolarizadoras y críticas tienen muchas caras. La sujeción del Estado como forma de control es uno de los argumentos más comunes, al igual que la mercantilización de la educación y su asociación exclusiva a la posibilidad laboral, como si esa fuera su única función social. Esos espacios, sin embargo, si no se ocupan

${ }_{15}$ Este texto es un extracto de Mémoires d'avengle (1990), que Derrida escribe tras una visita a una exposición de dibujos sobre ciegos en el Museo del Louvre. En De Pereti, C. y Vidarte, P.: Derrida (1930), Madrid, Ediciones del Orto, p. 76. 
desde «lo público», serán copados por lo privado. Y es ahí que el hecho educativo se vuelve pedagógico y, consecuentemente, político. El debate acerca de a quiénes pertenecen los niños y las niñas se ha reabierto. Y quienes niegan a la escuela una función socializadora, con derecho a la injerencia en la formación democrática y constitucional, están dando pasos agigantados hacia leyes propias que podrían hacer imposible una convivencia ya de por sí difícil.

Conviene recordar al respecto la reciente polémica en torno al pin parental y al debate sobre «a quién pertenecen» los hijos. El tema nos remite sin duda a revisiones del sentido de un Estado educador. Como cualquier hecho, un Estado totalitario supondría una amenaza para la formación, pero no puede obviarse a la ligera la contribución de los Estados democráticos a la conformación de la ciudadanía y al derecho universal. Si el Estado no garantiza la educación, el ars erótico no tiene sentido. Pero esa es la menor de las dificultades. A colación de la de nuevo vigente controversia sobre los límites del adoctrinamiento, es urgente recordar que toda política educativa contiene una ideología y que fue necesario en este país establecer un código aconfesional que permitiera secularizar la educación e incorporar a la mujer al sistema con pleno derecho epistemológico.

Sin la criticada «tendenciosidad» las mujeres no habrían salido de la esfera doméstica. Esta «politización» de la educación requiere partir de un hecho básico y legal, que es el cumplimiento de la Constitución. Claudio Lozano ofrecía un retrato clarificador de un «kulturkampf español» en el escenario de la II República. En este retoma las declaraciones de Gordón Ordás en el debate del proyecto de Constitución (Diario de Sesiones de Cortes):

Para que los hombres puedan ser así, nada mejor que la enseñanza. Lo sabe bien la Iglesia, y por eso quizá a lo que más se resiste de todo es a perder su influencia sobre el alma del niño. Con espanto nos citaba aquí el señor Molina Nieto, con ocasión de la sesión del jueves, una frase de Danton, que nosotros, con regocijo, hacemos nuestra: «el niño es de la patria». El niño es de la patria, y no solamente tiene derecho la patria, sino que tiene el deber de formarle. Es casi un crimen de lesa patria entregar la formación de quien ha de ser el ciudadano del porvenir a colectividades con miras parciales de este mundo o con miras muy amplias de otro mundo. El Estado, que tiene la responsabilidad del Poder, tiene la obligación de formar los ciudadanos que han de ejercer este poder $[\ldots]^{16}$.

Esta afirmación pone en entredicho la traducción de injerencia como adoctrinamiento. Ese vínculo de pertenencia al Estado ha de servir para garantizar un lugar de encuentro entre quienes, de no ser por el Estado, jamás podrían acceder a la educación, pese a la crítica de la escuela como esfera de control o como espacio de reproducción de la desigualdad, pese al choque cultural y las insaciables búsquedas de integración y normalización que son un reto siempre. Todos los hijos e

16 Lozano, C.: «Un Kulturkampf español: La pugna del Estado-Iglesia por la enseñanza durante la Segunda República», en VerGARA, J. (coord.): Estudios sobre la secularización docente en España, Madrid, Uned, 1997, p. 165. 
hijas son del Estado como mínimo, en la medida en que son ciudadanos con derecho a un espacio de formación, de socialización, de aprendizaje de comunidad, y también de indignación colectiva, de resistencia y de búsqueda de justicia en caso de serles negados sus derechos constitucionales.

El Estado tiene el «deber», la «responsabilidad» de abrir las puertas al conocimiento y a unos valores comunes para la convivencia y para la vida buena de sus ciudadanos, que son parte y destino al mismo tiempo de esa construcción. Así que quizá la fórmula no sea «los hijos son del Estado», sino «el Estado son los hijos». Y este es el rostro político del que no puede desprenderse jamás la educación, pese a quien pese.

Las relecturas e interpretaciones generan la misma propensión a la ruina que el ars erotica. Educar, escribir y crear no se suscriben nunca a la norma de lo único, sino al caos de lo probable. Derrida analiza, por hacer una analogía que podría ejemplificar el vértigo de la siembra. Se sabe que Nietzsche no tuvo grandes discípulos en vida y que, sin embargo, es uno de los filósofos de mayor alcance en nuestro tiempo, lo que no significa que hayamos llegado a una interpretación «definitiva» de su legado. Es desde esta premisa de pertenencia a un colectivo desde donde el amor, el compromiso y la responsabilidad hacen posible el encuentro sápido con el otro y con la otra. Origen y destino, se enseña y aprende a saborear el proceso de conocer y de valorar la necesidad de lo común. Cuando se produce la verdadera experiencia del encuentro maestro-discípulo, el tiempo del amor se vive como superación del tiempo. Cuando no hay alumno ni maestro que se encuentren, queda sabor a destiempo, aunque haya método, como se ha visto con la pandemia. La virtualización sobrevivió porque los lazos se crearon previamente. Una enseñanza virtualizada no se traduce necesariamente en aséptica, pero los ajustes que requiere exigen unas estrategias metodológicas cuyas exigencias no se ciñen a la realidad laboral de los tiempos de crisis.

Para Ernesto Grassi, la verdadera sabiduría de que surge la historia se concreta en el arte de hablar, que habla en y mediante el diseño de ejemplos ${ }^{17}$. El autor apunta además a una idea reveladora de esa dialéctica: la decadencia del lenguaje como decadencia de la historia: «La decadencia de una lengua da fe de la decadencia de un mundo, de su fuerza y de sus costumbres; señaliza la desaparición de una «visión», de una «interpretación» de las relaciones humanas y de las cosas, revela la desaparición de una actividad metafórica» ${ }^{18}$. La retórica es arte y arma al mismo tiempo.

Pero este riesgo no debe alentar la tentativa de la desescolarización heredada de Ivan Illich, que a veces es retomada con fuerza. Al riesgo de que las palabras no caigan al vacío, de que no lleguen a ninguna parte, cabe añadir la crisis institucional a la que asistimos. El debate pedagógico trasciende a la propia institución en sus habituales fórmulas de seminarios, congresos o cátedras y se deja oír en

${ }_{17}$ Grassi, E.: El poder de la fantasía. Observaciones sobre la historia del pensamiento occidental, Barcelona, Anthropos Editorial, 2003, p. I07.

${ }_{18}$ Ídem. 
numerosos foros y trabajos en la Red un mosaico informe de opiniones que en muchos casos dejan entrever escepticismo, descrédito y rechazo a la escuela. Pese a las lógicas críticas de que los docentes son necesariamente susceptibles, hemos de sortear una serie de requerimientos que anulan el entusiasmo, el tiempo y la libertad de ser y de decir, ya sea por los sistemas de control tan férreamente perpetrados por los ideólogos de un pensamiento único, definido por criterios mercantiles, ya porque los requerimientos burocráticos extenúan la voluntad y la fuerza necesarias para seducir con la palabra.

A ello hemos de sumar el cuestionamiento generalizado de la utilidad social del profesor en medio de otra consideración, también común, de que la educación formal es ya no solo un espacio inútil, sino insano para el desarrollo de los jóvenes. Este descrédito ha invitado a algunos padres a asumir la función de docentes. Esto acontece, curiosamente, en el mismo escenario pretendida y falsamente globalizado en el que Unicef (2007) emite informes que estiman que 93 millones de niños en edad de asistir a la escuela primaria están desescolarizados.

Esos casos de abandono deliberado de las escuelas por parte de padres-profesores, cada vez más frecuentes, son, pues, un síntoma anunciador de cambio, pero suponen un porcentaje ridículo por lo pronto en una escala planetaria. En la mayoría de estos casos se trata de un ejercicio de, llamémoslo, libertad, por parte de quienes pueden optar a esta renuncia sin privar a sus hijos de opciones de futuro, puesto que de alguna manera pueden garantizar (si es que ello es posible) o cuando menos intentar procurar una alternativa laboral a sus hijos. Asimismo, esta renuncia no se traduce siempre en esa radical desescolarización, sino que, esbozando argumentos inspirados en criterios cualitativos de un deseo subjetivo de más calidad, o de otra calidad, o de un tipo concreto de educación, que pueda ser más/menos práctica, más/menos afectiva, más/menos tradicional, más/menos restrictiva, más/menos disciplinada, más/menos ociosa, etc., deciden buscar propuestas educativas alternativas.

Las metodologías que se proponen desde algunos proyectos pretenciosamente alternativos (como la escuela Waldorf o los derivados de los discursos de pensadores como Ken Robinson, de gran audiencia en Youtube, quien, desde la ironía, plantea que la escuela aniquila la creatividad, especialmente en el $\operatorname{arte}^{19}$ ) no son en absoluto novedosas. Estos pueden encontrarse ya en la tradición pedagógica escolanovista heredera de las propuestas rousseanianas, pestalozzianas y froebelianas que alcanzan hasta la escuela colaborativa de Célestin Freinet o los métodos de Maria Montessori, entre otros.

El deseo de ruptura con los postulados tradicionales se ha venido manifestando además en una búsqueda histórica de diversos modelos de enseñanza-aprendizaje, como el conductista (Paulov, Skinner...), el constructivista (Vygotski, Piaget,

19 Ahora bien, cabe preguntarse, ante el reclamo de esta carencia, el para qué de la misma. Si el objetivo creativo es servir a una estética mercantil, que alimenta la cultura del selfish y no es utilizada para la creación de posibilidades altermundistas, quizá el reclamo carezca de interés ético-pedagógico en nuestra propuesta. 
Ausubel...), el modelo Sudsbury, etc., y es una constante desde la creación de los sistemas nacionales de educación decimonónicos. Estos modelos tienen en común la necesidad de redefinición de un nuevo vínculo en la relación maestro-alumno, pero no siempre se fundan en una lectura político-económica crítica del sistema (salvo excepciones, como la pedagogía del oprimido de Paulo Freire), sino que en muchos casos se limita a una cuestión meramente estratégica y metodológica. Esto es, lo que cuestionan muchas veces no es la injusticia sistémica o si el sistema es integrador, o si es ético.

La hipótesis que proponemos es que este rechazo voluntario a la institución no implica necesariamente un cuestionamiento del modelo económico hegemónico, ni una lectura de las desigualdades, ni una crítica a la segregación. En muchos casos, se trata de una cuestión únicamente metodológica: que el niño no sienta presión, que aprenda por sí mismo, a su ritmo, que pueda disfrutar de su tiempo de ocio..., es decir, que sea feliz. Y está claro que sería un encomiable objetivo, que podría ser el olvidado objetivo al que debíamos estar llamados, sin el imperativo del «compite», del «sé eficiente». Lo sería, como posibilidad y lo es como reto. Pero si este objetivo es formulado solo por una elite acomodada y ya feliz que pretende preservarse, si esa pretensión de felicidad no contiene el deseo de la felicidad de los más, otro modelo de mundo no es posible y estos métodos son insuficientes.

Así que estas propuestas son, en cierto modo, un privilegio. No es el tipo de desescolarización de los deprivados, de los marginados, de los invisibilizados del mundo.

Hoy en día [denuncia Daniel Pennac] existen en nuestro planeta cinco clases de niños: el niño cliente entre nosotros, el niño productor bajo otros cielos, así como el niño soldado, el niño prostituido y, en los paneles curvos del metro, el niño moribundo cuya imagen, periódicamente, proyecta sobre nuestro cansancio la mirada de hambre y abandono. Son niños, los cinco. Instrumentalizados, los cinco $^{20}$.

Aquellos que malviven en condiciones de extrema pobreza acaso ni se plantean qué es educación. Y los que tienen acceso a sistemas nacionales, pero en condiciones de marginación, cuando no se convierten en absentistas reiterados o abandonan el régimen, son reabsorbidos en programas compensatorios que lejos de integrar, como pretenden, estigmatizan a través de derivaciones a programas curriculares «adaptados» que les permiten obtener las titulaciones elementales y suelen acabar bien abandonando, como se ha dicho, bien consiguiendo, con suerte, un trabajo precario. Cuando continúan sus estudios y se convierten en alumnos ejemplares, responsables, dóciles, entonces el sistema los considera un triunfo propio y crea un sentimiento de gratitud y deuda.

20 Pennac, D.: Mal de escuela, Barcelona, Debolsillo, 2009, p. 236. 
Eso se llama la instrucción pública, es decir, la instrucción del pueblo empírico programada por los representantes del concepto soberano del pueblo. De esta forma, la Instrucción Pública es el brazo secular del progreso, el medio de igualar progresivamente la desigualdad, es decir, de desigualar indefinidamente la igualdad. Todo se juega siempre sobre un único principio, la desigualdad de las diferencias ${ }^{21}$.

De Sócrates (acaso el inspirador intelectual de la Escuela Nueva) nos ha quedado una mayéutica pedagógicamente manipulada al servicio de los Estados-nación que sirven a los intereses de las grandes corporaciones a través de metodologías de partos infértiles, de saberes técnicos especializados maquillados de siglo XXI, como si la técnica no estuviera ya en el origen del mundo, como ya reclamara Heidegger (la tecnología surgió desde que el hombre tomara la primera piedra). Una pedagogía que utiliza metodologías de una mayéutica de la tecné que deviene episteme en el mejor de los casos, y como naturaleza en el peor, cuando se afirma que el alumnado contiene genéticamente el manual del Ipad.

Claro que este análisis solo vale para las sociedades postindustriales tardocapitalistas. Y la mentira pedagógica está contenida en la trampa de la globalización. Autores como Chomsky o Ulrich Beck, entre tantos, no se cansan de recordarnos que globalización es un término de propaganda, que no puede ser leído unilateralmente, como si el mundo fuera uno e igual, o, acaso, como si los destinos de los espacios aún no globalizados en ese sentido uniforme estuvieran marcados por la fatalidad del «no podrán ser de otro modo».

La globalización ha servido para configurar un imaginario de alcance mundial de todo aquello que satisface los intereses mercantiles de las corporaciones, apoyadas, en muchos casos, por los poderes estatales. Se globaliza la idea de libertad mercantil, mientras se adoptan medidas proteccionistas; se globaliza la idea de universalismo mientras, paralelamente, se promueven las luchas interétnicas e interestatales en algunas zonas del planeta; se globalizan los costes públicos y sellan el globo con una cuerda los que privatizan los beneficios, paradójicamente generando cada vez más la desigualdad y concentración en manos de unos pocos las grandes fortunas del planeta. Tras la globalización se esconde también una pedagogía de la trampa que sirve a los mismos intereses. ¿Quiénes están dando las pautas de la política educativa hoy? Está claro que no son pedagogos o, mejor dicho, no son un tipo de pedagogos que cuestiona el sistema, como es lógico. Dicho de otro modo: el vínculo política y pedagogía es ineludible, ahora bien, el tipo de relación no ha sido siempre el mismo, como tampoco los regímenes donde se crea ese vínculo. El problema, a nuestro juicio, surge cuando esa relación es unilateral (la corporación dicta al Estado, el Estado no marca la pauta a la corporación).

La democracia está en jaque. Ya Foucault había dejado patente que las escuelas funcionaban como dispositivos de control y mostrado pertinentemente las relaciones de poder que las atraviesan. Y mucho antes Nietzsche había denunciado ${ }^{22}$

${ }_{21}$ RANCIÈRE, J.: El maestro ignorante, Barcelona, Laertes, 2002, p. I69.

22 Nietzsche, F.: Sobre el porvenir de nuestras escuelas, Barcelona, Tusquets, 2000. 
que estas se habían convertido en fábricas de cultura. Y podríamos referir aquí también a los teóricos críticos de la reproducción que dejaron en evidencia la falacia de la meritocracia.

La imagen de este alumno ideal [retomando nuevamente a Pennac] se dibuja en el éter cuando oigo pronunciar la frase: «todo se lo debo a la escuela de la República». No pongo en cuestión la gratitud de quien la pronuncia: "Mi padre era obrero y todo se lo debo a la escuela de la República». No minimizo tampoco los méritos de la escuela: «soy bijo de inmigrante y todo se lo debo a la escuela de la república». Pero, y es más fuerte que yo, en cuanto escucho esta manifestación pública de gratitud, veo proyectar una película [...] a la gloria de la escuela, es cierto, pero sobre todo a ese niño que habría comprendido, desde su primera hora en el parvulario, que la escuela de la República estaba dispuesta a garantizarle el porvenir siempre que fuese el alumno que ella esperaba! ; Y pobres de aquellos que no respondan a esas expectativas. ${ }^{23}$

Los que respondieron a las expectativas tuvieron garantizado el porvenir, al menos hasta antes de que el porvenir fuera presente. Aquí germinó uno de los vínculos institucionales entre saber-poder, que no contemplaba las multiplicidades, sino que se sustentaba en una unicidad subvertida: lo que era masa sometida conviértase, aunque sea falazmente, en masa soberana. El resultado es una unicidad de fondo sobre la que emerge el capitalismo, y uno de los hechos que han propiciado el desarrollo del pensamiento único.

La aplicación del racionalismo en la esfera política, y una de sus mayores contradicciones, se ha sustentado en una idea de «estatus» que en nuestro tiempo no parece ya practicable, en la medida en que su desvelamiento la ha descubierto tan impracticable como inauténtica, porque valida un pacto social jerarquizado, desigual y excluyente.

Los griegos habían utilizado la palabra Skbole para referirse al 'ocio', al 'tiempo libre que se invierte en buscar el conocimiento’. Podríamos decir que, en nuestro siglo, la escuela como sociedad disciplinaria (siguiendo de nuevo a Foucault) ha invertido esta significación y la ha traducido en 'ocupación que se invierte en buscar cómo entretener', y no en un continuar dando respuesta a las cuestiones fundamentales e irresueltas del proyecto civilizatorio, como si se hubieran resuelto, definitivamente, como si no fuera necesario repensarlas..., de manera que se ha ido tejiendo el vacío epistemológico con el que emerge y vence el pensamiento único.

Hasta aquí aceptamos la crítica a la escuela pública. Pero no debemos olvidar que es desde esta misma institución desde donde emergen o podrían emerger las alternativas y las posibilidades de transformación social. Es en este escenario desde donde debemos repensar la educación para el siglo Xxi y este el argumento con el cual intentamos salvar la potencia de una institución en crisis. Un marco en el que el papel docente está siendo sádicamente cuestionado.

23 Op. cit., p. 227. 
Profesores ¿para qué?, se preguntaba Georges Gusdorf, respondiéndose a sí mismo que

la maestría empieza más allá de la pedagogía. La maestría supone una pedagogía de la pedagogía [...] El maestro es aquel que traspasa la concepción de una verdad como fórmula universal, solución y resolución del ser humano, para elevarse a la idea de una verdad como búsqueda. El maestro no posee la verdad y no admite que alguien pueda poseerla. Le da horror el espíritu de propietario del pedagogo, y su seguridad en la vida, [...] El oscurantismo pedagógico busca asilo y refugio en el tecnicismo ${ }^{24}$.

Pero lo que la técnica ofrece son datos. El problema no estará en si la docencia es real o virtual, sino en si la pedagogía oficial, la que sirve a los intereses creados hegemónicos, cederá algún espacio al ejercicio hermenéutico y a que dicho ejercicio pueda seducir a las nuevas generaciones.

Planteaba Nietzsche en Humano, demasiado bumano: «¿Y cuál hubiese sido el más torpe de todos los educadores [...]? El fanático moral que cree que el bien no puede salir más que del bien ni puede crecer más que en el bien» ${ }^{25}$. Las propuestas desescolarizadoras apuntadas anteriormente se esconden tras el seductor velo protecnológico traducidas en incuestionable progreso, y bajo la tentación de la virtualización de las aulas. Si el riesgo del educador torpe ha estado servido (y aún lo está), no parece menos cierto que nuevas amenazas virtuales ofrezcan otras, y no menos difíciles, coordenadas para el ejercicio de hermenéutica social.

\section{El eros pedagógico}

Yo seré tu Espejo no significa «yo seré tu reflejo», sino «yo seré tu ilusión». Seducir es morir como realidad y producirse como ilusión. Es caer en su propia trampa y moverse en un mundo encantado.

Jean Baudrillard, De la seducción.

Los pedagogos, como los maestros, tendrán que asumir el reto de abordar ya no la cuestionada y complejizada función docente en los espacios acostumbrados, sino que deberán estar en disposición de resolver su redefinición y, sobre todo, de retomar el imprescindible cuestionamiento acerca de los qué, los cómo y los para qué deben sustentarla. La política cambia, pero el eros permanece y estará en la capacidad de fascinación y de crear vínculos donde podamos hallar tal vez la promesa de permanencia transformada y transformadora.

El eros pedagógico, es decir, el ejercicio de hipnotizar y estimular positivamente la sed de conocimiento podemos encontrarlo ya en la dialéctica mayéutico-irónica entre Sócrates y Platón. También se aprecia en los textos platónicos

24 GadotTI, M.: Historia de las ideas pedagógicas, Madrid, Siglo XXI Editores, 2002, p. 177.

25 Nietzsche, F.: El viajero y su sombra, Madrid, Edaf, 1999, p. I84. 
un canto al heroísmo del ejercicio de libertad de pensamiento y de la libertad metodológica. Las acusaciones contra Sócrates son claro ejemplo de ello. Sócrates no solo seduce a sus discípulos, sino que permite que Platón lo cuestione. No ha creado un discípulo, sino que ha contribuido a la formación de un pensador. Efectivamente, consideramos que el educere conlleva necesariamente la herejía y la traición. Lleva, asimismo, su propia libertad a los últimos límites cuando asume las consecuencias de sus acciones ante las acusaciones de introducir divinidades nuevas, de impiedad (asebeia) y de corruptor de juventud («les sorbes los sesos y los hijos te hacen más caso a ti que a sus padres» $)^{26}$. Esta expresión no nos resulta ni extraña ni caduca; esta expresión puede escaparse de la boca de cualquier padre/madre/tutor-a corriente ante la influencia que los «otros» ejercen en sus hijos. Como irónicamente hace observar Daniel Pennac ${ }^{27}$ a unos amigos que lamentan cuánto han cambiado los alumnos desde sus infancias y todos ellos subrayan el diferente color de la piel o el número -son más-. También hay semejanzas -dice Pennac- como que siguen madrugando mucho, portando pesadísimas mochilas, y los profesores siguen siendo «el manjar preferido en el menú de sus conversaciones», pero la diferencia fundamental «debe buscarse en otra parte: no llevan los jerséis viejos de sus hermanos mayores» ${ }^{28}$.

Makarenko, hijo de la Revolución de Octubre, el pedagogo del régimen, nos permite deducir que el eros pedagógico trasciende los dispositivos mismos que definen las políticas educativas a partir de la creación de los sistemas nacionales de educación. No se trata de una ideología, ni de un método, ni de una estrategia, sino de una invitación a la tentación de transformación. Y esta erótica es bidireccional, porque no existe sin maestro, pero tampoco sin discípulo. En una de sus más célebres obras, Banderas en las torres, la maestra (Nadiezhda Vsilievna) interroga a Igor Cherniavin.

Le reprocha que únicamente destaque en la materia que ella imparte (Literatura). Solo después de esa conversación, el joven Igor cambia su actitud ante los estudios. Igor la escuchaba embelesado:

Ella hablaba tranquila y pausada, lo que hacía más sugestiva la ola de cultura que envolvía sus palabras. A partir del día siguiente, Igor apretó de firme en las restantes asignaturas. Entusiasmado por el esfuerzo, sintió crecer el aprecio a su propia persona y decidió firmemente estudiar con aplicación. A las fiestas de mayo llegaba con sobresaliente en todas las asignaturas, y en la colonia había una sola persona que no le cedía en los estudios: Oxana Litóvchenko. Igor no advirtió cuándo había

26 En la «Introducción» a Platón: Apología de Sócrates, Madrid, Clásicos del pensamiento Alhambra, 1985, p. 3I. «La institución familiar era fuerte en Atenas: el no honrar a los padres, levantarles la voz, negarles el sustento, era condenado con la atimía o pérdida de los derechos ciudadanos. Los candidatos a cargos públicos eran examinados dokimasia sobre su conducta familiar. Y Sócrates reconoce que su pasión de interpelar al personal, la ha contagiado: "los que me siguen no sólo disfrutan escuchándome, sino que después, ellos se atreven a interpelar a los que encuentran"», p. 32.

27 Pennac, D.: op. cit., p. 232.

${ }_{28} \quad$ Ibid., pp. 232-233. 
cambiado su carácter. En ocasiones, sentía el deseo de ironizar y de hacerse el original; a primera vista, nada había cambiado en él; no obstante, sus palabras ya eran otras, más discretas, de más peso; y también su humor era otro ${ }^{29}$.

Y como este, tantos ejemplos. Cécile Ladjali, en Elogio de la transmisión, convence epistolarmente a Steiner para que dialogue con sus alumnos en un instituto de zona marginal francesa. Y el resultado, como cabe esperar, fue un éxito: el entusiasmo de unos jóvenes fascinados por la presencia de un maestro de maestros, a través de su maestra. La erótica del entusiasmo no puede emanar más que de la voluntad individual de un modelo de profesora que sabe que sin eros no hay logros. Y esto no puede encomendarse como una prescripción programada y obligatoria. Es un ejercicio de devoción y afecto, y, en tanto tal, no es prescriptible. Por eso este discurso no tiene cabida en una pedagogía en la cual, salvo que uno lleve por nombre Unamuno, hay que pedir disculpas por atreverse a hablar de amor.

De una enseñanza sin eros docente, las probabilidades dan como resultado tecnócratas, autómatas o bien, caricaturescamente, el esperpento rabelaisiano, que nos ofrece acaso uno de los ejemplos más claros del pedagogo antihéroe en la figura de maese Pánfilo y cuya lectura debe trascender el carácter jocoso que lo atraviesa. Detrás de la ironía discursiva, el esperpento nos muestra lo grotesco de lo posible a la manera de thanatos pedagógico como oposición al eros que estamos intentando definir. El lector reconoce en el esperpentizado personaje del alumno Gargantúa a cualquier anónimo real; y es en esa conexión donde se desata la carcajada, que va más allá de un mero ejercicio de Suspection of disbelief ${ }^{30}$, esto es, de dejar de enjuiciar la credibilidad, como sucede en los relatos fantásticos o de terror. No se hace juicio el lector de la verosimilitud, sino una asociación entre el personaje esperpéntico que es Gargantúa y cualquier persona real que, hiperbolizada, encarnaría al personaje.

El esperpento contiene así lo trágico y lo cómico. De modo que cuando analizamos con qué esmero se afana Grangaznate en procurar a su hijo Gargantúa la mejor de las educaciones posibles, y se hace comparar a sí mismo con Filipo de Macedonia y a su criatura con Alejandro, podemos percatarnos de que educar es mucho más que medios y voluntad. Así podemos leer en su irrisoria megalomanía la de tantos padres. (Capítulo XIV «De cómo un sofista instruyó a Gargantúa en letras latinas»). Pero ya solo el tono narrativo nos da pautas suficientes para anticipar el fracaso al que está condenado Gargantúa. En el capítulo siguiente (Capítulo XV «De cómo Gargantúa fue confiado a otros pedagogos») el francés nos regala ya a un antihéroe de la docencia en el personaje de maese Pánfilo, quien no solamente había dado muestras de una gran ineptitud como profesor cuando el desventurado Gargantúa queda en evidencia, tras años de esmeradísima

29 Makarenko, A. S.: Banderas en las torres, Moscú, Editorial Progreso, 1976, pp. 354-355.

30 'Suspensión de incredulidad', es la traducción de este concepto acuñado por Samuel Taylor Coleridge en 1817 . 
instrucción libresca por parte de su maestro, ante un paje que «aún no tiene doce años» ${ }^{31}$. Grangaznate asume el reto de don Felipe de Marais, virrey de Papeligosse, quien cuestiona las lecturas, el método y a los preceptores que aquel ha escogido. Este desafío consiste en medir a Gargantúa con el joven paje. Y mientras el niño dio muestras de extraordinaria elocuencia, un ridiculizado Gargantúa se limitó, y citamos textualmente, a «llorar como una vaca y taparse la cara con su gorro, de tal forma que no fuera posible arrancar una palabra, como es imposible arrancar un pedo a un burro muerto" ${ }^{32}$.

Escribe Ricoeur: «El mito, cuando dice de qué modo empezó el mundo, dice de qué manera la condición humana fue engendrada en su forma globalmente miserable»33. Un sistema educativo que promueve la disciplina y la obediencia, por poner un ejemplo, contiene la posibilidad del bien, pero, en su perversión más radical, la disciplina del discípulo (ambas, conceptos desprendidos de la misma fuente etimológica) obediente puede devenir, como de hecho ha sucedido, en prácticas fanáticas de lesa humanidad. ¿Y cómo se define el orden en el que miserias y grandezas se suceden? Sirvan de ejemplo de la posibilidad del desvío y de que la justificación de las miserias, el mal, la transgresión, la provocación, la perversión... no proceden únicamente de carencias materiales (como defenderían los marxistas) o espirituales (como defendía el humanismo); es una cuestión de residencia, de naturaleza, de humanidad; por eso quizá sea inmune a fórmulas didácticas.

Es posible que el «ejercicio de taponar líneas de fuga» tan frecuentes en las casas del saber no esté exento de responsabilidad en la conformación de personas. Puede ser un argumento freudiano buscar en la represión la vía de escape. Pero si se hubiera naturalizado la potentia de la huida en lugar de imponer su ocultación más allá del inconsciente (en lo más profundo del ser), Humbert se hubiese puesto a pintar en vez de a seducir a su nínfula. La mayoría de los personajes que nos han servido de ejemplo tienen en común un paso intenso y fervoroso por los sistemas educativos.

El límite entre pensar y hacer es frágil. En El inmoralista de André Gide el protagonista confiesa: «Enseguida comprendí que las cosas peor reputadas (la mentira, por sólo citar ésta) sólo resultan difíciles de hacer en la medida en que jamás se han hecho, pero que todas se convierten, y muy aprisa, en fáciles, agradables y sencillas de repetir, y enseguida, en naturales». Esta es la premisa sobre la que sustenta el sadismo. Sobre papel no tiene especial relevancia colocar un guion entre las palabras personaje y persona. Al contrario, sirve para recrear las consecuencias del bien y del mal en un marco de ficción, pero posible. El filo de la navaja solo se muestra cuando se transgreden los límites y se pasa de la potencia al actio. El eros, como concepto, encierra seducción, pero es un concepto sin

Rabelais, F.: Gargantúa y Pantagruel (los cinco libros), Barcelona, Acantilado, 20II, p. I5I.

Ibid., p. I52.

33 Ricoeur, P.: El mal. Un desafío a la filosofía y a la teología, Buenos Aires, Amorrortu, 2006, p. 29 . 
contenido ético. Esto significa que el contenido le es dado por los partícipes de la relación. Y una relación educativa es siempre una relación de poder. Es decir, no es tomable por la fuerza. Se puede prohibir el mal, pero nada garantiza el cumplimiento del imperativo. Algo similar sucede en la relación de influencia entre maestro y discípulo. Un maestro expone y se expone. Sócrates se declaró, pero ¿podemos considerarle un corruptor de la juventud? ¿Es responsable de las acciones de sus alumnos?

Estos cuestionamientos de alguna manera paralizan y enmudecen a muchos docentes que temen no solo posibles represalias de carácter disciplinario, sino las consecuencias de su influencia: la de una educación para la libertad. También la libertad es inexpugnable y habrá de ser el alumno quien decida sus propios límites. Ese riesgo ya no nos pertenece.

Como dice Steiner:

La enseñanza auténtica puede ser una empresa terriblemente peligrosa. El maestro vivo toma en sus manos lo más íntimo de sus alumnos, la materia frágil e incendiaria de sus posibilidades. Accede a lo que concebimos como el alma y las raíces del ser, un acceso del cual la seducción erótica es la versión menor, si bien metafórica. Enseñar sin un gran temor, sin una atribulada reverencia por los riesgos que comporta, es una frivolidad. Hacerlo sin considerar cuáles pueden ser las consecuencias individuales y sociales es ceguera. Enseñar es despertar dudas en los alumnos, formar para la disconformidad. Es educar al discípulo para la marcha ${ }^{34}$.

Una marcha que escapa a cualquier vacilación previa que hayamos podido hacernos los hijos infinitos de la decadencia. El miedo de Nietzsche a la degeneración es raíz del vitalismo: lo que degenera atenta contra el principio de la vida, es hostil a la vida: se vive el cuerpo, se vive la lengua y hasta la propia muerte se vive como algo más que como cuerpo roto. Es la degeneración no de cómo se piensa, sino de la imposibilidad del pensamiento divergente, precisamente lo que degenera la civilización y el principio de creación del ser humano. Educar es atreverse a quebrar los principios de la cultura, como desafío constante, sin garantía del resultado. Atreverse a decir, a usar la palabra como traductor limitado de un pensamiento. Como arte y como arma, indefectiblemente, como se ha dicho.

Ningún sistema probado ha sido capaz de garantizar nada que satisfaga las necesidades y el buen vivir y, en este sentido, ninguna apuesta novedosa tiene nada que perder, aunque pueda tener como desenlace un estrepitoso fracaso. De modo que está todo por ganar durante la marcha y pese al riesgo de error en la interpretación del maestro, de una equívoca «resemantización» del discurso al servicio de proyectos que escapan a la intención del texto y de la palabra. Claro ejemplo fue la interpretación que el nazismo hizo de Nietzsche. Aún pervive el enigma semántico entre el Fübrer nietzschiano y el Fübrer hitleriano. Este último, como plantea Derrida, «también se pretendió maestro del pensar, un guía de doctrina

34 STEINER, G.: La lección de los maestros, Madrid, Siruela, 2004, pp. IOI-IO2. 
y de formación escolar, un docente de la regeneración. Ello sería tan necio y políticamente adormecedor como decir: Nietzsche nunca quiso eso, nunca pensó eso, lo habría vomitado o no lo entendía así, no le prestaba esos oídos», pero no es de interés esa hipótesis, porque «Nietzsche muere, como siempre, antes que su nombre, y no se trata de saber lo que habría pensado» ${ }^{35}$.

El argumento esencial de Derrida al respecto es que

los efectos o la estructura de un texto no se reducen a «su verdad», al querer decir de su autor presunto, y ni siquiera al de un signatario pretendidamente único e identificable. Y aun cuando el nazismo, lejos de ser la regeneración invocada por esas conferencias de 1872, fuera solo un síntoma de la descomposición acelerada de la cultura y de la sociedad europea así diagnosticada, todavía restaría explicar por qué la degeneración reactiva puede explotar el mismo lenguaje, las mismas palabras, los mismos enunciados, las mismas consignas que las fuerzas activas a las cuales se opone ${ }^{36}$.

La escuela, si no es ya más espacio para la política, no puede dejar de ser lugar de «lo político». La escuela no forma políticos, pero los políticos han pasado por la escuela. Cuando la corrupción es un problema nacional es síntoma y reflejo de una formación mejorable, al menos una formación que parta del proyecto con que se iniciaba este trabajo. Una buena traducción del legado discursivo y una excelente comprensión lectora se evidencian aquí destrezas ineludibles que acometer.

Sabemos que no hay ars erotica pedagógica, más bien, que la rutinización de la relación educativa está pidiendo a gritos su transformación en otro tipo de relación, aquella que evoque la excepcionalidad de la experiencia, aquella mediada por el eros como fuerza, como demon que enlaza razón y pasión, eternidad y finitud, desde el itinerario de los que nos precedieron. Eros aquí es siempre tensión, siempre aspiración, y transforma el saber en vértigo. Una pedagogía transitada poéticamente, eróticamente, vuelve sujeto todo objeto, vuelve prójimo todo ajeno. Si el vínculo maestro-alumno, como ejercicio de influencia, ha sobrevivido hasta hoy como potencia de ambivalencia axiológica, es posible que resista el nuevo episodio que se inaugura.

Los hombres anuncian a otros hombres en cuanto -también en los más eminentes tonos- hablan de las posibilidades humanas. Es la lengua como melos, mitos y logos en la que los hombres invitan a sus semejantes a convertirse en hombres. Quien corresponde a la invitación del discurso sobre las más eminentes posibilidades humanas va a parar al centro del proceso de humanización. Al penetrarse de la impotencia de tales discursos, los individuos experimentan el impulso de no sólo ser oyentes de la palabra, sino convertirse en sus autores. Desde siempre fue la humanización un suceso en el que predicadores eminentes proponían a sus

35 DerridA, J.: Otobiografías. La enseñanza de Nietzsche y la política del nombre propio, Buenos Aires, Amorrortu, 2009, p. 70.

${ }_{36}$ Ibid., pp. 70, 7I. 
semejantes modelos de humanidad, historias ejemplares de los antepasados, los héroes, los santos, los artistas. A esa fuerza demiúrgica de la lengua la llamo promesa. El hombre tiene que ser prometido al hombre antes de someter a prueba, en sí mismo, lo que puede ser. El que no ha oído nunca las historias de los dioses, héroes, santos, profetas y artistas, es muy difícil que quiera o pueda ser un dios, héroe, santo, profeta o artista. El discurso ha de haberse referido a "grandes hombres», en tercera persona, antes de que un individuo pueda dar en la ocurrencia de ser él mismo uno de semejantes sujetos. La lingüistica del entusiasmo trata de esas transiciones ${ }^{37}$.

Queda clara hasta aquí nuestra posición antipragmática desde una apuesta arriesgada por el cruce, el atravesar poético de la vida en el mundo. Pero no queremos confundir esta posición con la absurda y lírica negación de lo prosaico. Nada más lejos de nuestra intención que abandonar el mundo antes de entrar en él.

En esta época de forzados consensos, de silencios cobardes, de paz contenida, irreal, que encierra tras sí la postergación claudicante de antagonismos no resueltos, en los que, cínicamente, ha sido todo dicho; en esta época en que la escucha se ha convertido en sacrificio (ya nadie lee, ya nadie dice, ya nadie escucha), rescatar la palabra, redignificarla, relegitimizarla, solo es posible devolviéndole el eros. Es delgada y frágil la línea que separa el educere del seducere, 'seducir, llevar a un lugar apartado, separar, llevar a un lugar que es secretus, 'fuera de sí'.

En cualquier caso, la invitación es la osadía de una educación que aglutine las didácticas de la vida y de la muerte desde el entusiasmo y la pasión, pero con la conciencia desvelada ante la realidad. La pandemia, la dificultad del encuentro quizá empiece pronto a mostrarnos las estrategias de las nuevas e intensas miradas, ahora que las mascarillas cubren buena parte de los rostros y opacan las voces. El desafío es que no sean amordazadas por el peligroso aparataje de posverdad que se está construyendo. Los nuevos cantos de sirena van a requerir coros de lucidez que inviten a salvar el derecho a un lugar en el mundo. De nuevo retomamos el imprescindible ensayo La utilidad de lo inútil de Ordine para concluir, con palabras prestadas, afirmando que «abandonar la pretensión de poseer, saber convivir con el riesgo de la pérdida significa aceptar la fragilidad y la precariedad del amor» ${ }^{38}$. El amor es el motor de la seducción.

\section{Bibliografía}

Agamben, G.: Lo abierto. El hombre y el animal, Valencia, Pre-textos, 2005.

Arendt, H.: La condición humana, Barcelona, Paidós, 1993.

BAUM, E.: «El rol de las emociones en la esfera pública», Revista Latinoamericana de Derechos Humanos Volumen, Universidad Nacional Costa Rica, 23, I semestre (20I2).

${ }^{37}$ SloterdijK, P.: Extrañamiento del mundo, Valencia, Pre-textos, 2008, pp. 40-4I. La cursiva es nuestra.

${ }_{38}$ ORdine: op. cit., p. I2I. 
De Pereti, C. y Vidarte, P.: Derrida (1930), Madrid, Ediciones del Orto, 1998.

DerridA, J.: Otobiografías. La enseñanza de Nietzsche y la política del nombre propio, Buenos Aires, Amorrortu, 2009.

Gadotti, M.: Historia de las ideas pedagógicas, Madrid, Siglo XXI Editores, 2002.

Grassi, E.: El poder de la fantasía. Observaciones sobre la historia del pensamiento occidental, Barcelona, Anthropos Editorial, 2003.

Makarenko, A. S.: Banderas en las torres, Moscú. Editorial Progreso, 1976.

Nietzsche, F.: Sobre el porvenir de nuestras escuelas, Barcelona, Tusquets, 2000.

Nussbaum, M.: Emociones políticas. ¿Por qué el amor es importante para la justicia?, Barcelona, España, 20I4.

Nietzsche, F.: El viajero y su sombra, Madrid, Edaf, 1999.

Ordine, N.: La utilidad de lo inútil, Barcelona, Acantilado, 2017.

Pennac, D.: Mal de escuela, Barcelona, Debolsillo, 2009.

Platón: Apología de Sócrates, Clásicos del Pensamiento, Madrid, Alhambra, 1985.

Rabelais, F.: Gargantúa y Pantagruel (los cinco libros), Barcelona, Acantilado, 201 .

RANCIÈRE, J.: El maestro ignorante, Barcelona, Laertes, 2002.

Ricoeur, P.: Sí mismo como otro, México, Siglo XXI, 1996.

Ricoeur, P.: Lo justo, Madrid, Caparrós, I999.

Ricoeur, P.: El mal. Un desafío a la filosofía y a la teología, Buenos Aires, Amorrortu, 2006.

SEN, A.: La idea de la justicia, Madrid, Santillana, 2010.

Sloterdijk, P.: Extrañamiento del mundo, Valencia, Pre-textos, 2008.

Steiner, G.: La lección de los maestros, Madrid, Siruela, 2004.

Vergara, J. (coord.), Estudios sobre la secularización docente en España, Madrid, Uned, 1997. 
